\title{
Removal of Arsenic Using Hydrated Mixed Trivalent Iron-Aluminum Oxide Adsorbent: Prediction of Column Performance
}

\author{
JAYITA DUTTA \\ Department of Chemistry, Ranaghat College, Old Berhampore Road, Ranaghat, Nadia, \\ West Bengal-741 201, India. \\ *Corresponding author E-mail: jd_scottchem @ yahoo.co.in \\ http://dx.doi.org/10.13005/ojc/360311
}

(Received: May 10, 2020; Accepted: June 17, 2020)

\begin{abstract}
The performance of the column experiment for the removal of arsenic from groundwater by using the method of adsorption using hydrated mixed trivalent Fe-Al oxide as adsorbent in the agglomerated nanoparticle form was explored. Efficiency of the adsorbent was scrutinized by carrying out the experiment with field groundwater sample, spiked with arsenic solution of a particular concentration at $\mathrm{pH} 7.5$ and $30^{\circ} \mathrm{C}$ at variable experimental conditions. For characterization, FTIR was done for the mixed binary oxide, pure $\mathrm{Fe}_{2} \mathrm{O}_{3}$ and $\mathrm{Al}_{2} \mathrm{O}_{3}$. Two breakthrough curves were plotted by varying the bed-depth of the adsorbent and the outflow rate to ascertain the condition for maximal scope of adsorption. The kinetic parameters from the breakthrough curves were evaluated using Thomas and Adams-Bohart model analyses. The result of the column study showed that, the adsorbent performed efficiently as a cost-effective scavenger of toxic arsenic from groundwater.
\end{abstract}

Keywords: Arsenic, Hetero-oxide adsorbent, Column experiment, Breakthrough curves.

\section{INTRODUCTION}

Suffering of mankind from groundwater pollution arising out of arsenic poisoning has now become a worldwide environmental threat especially in the Bengal belt. In West Bengal, predominantly in the areas of Malda, Murshidabad, 24-Parganas, Howrah and Hooghly unfortunately exceeding 40 million people are staying above the recommended level of arsenic according to World Health Organization (WHO) guideline ${ }^{1}$. Mostly the poor people are the sufferers through their ingestion of arsenic containing drinking water, shows the symptoms of arsenicosis ${ }^{2}$. So, in recent times it becomes a matter of serious bothering about arsenic related incurable health problems and remedy from its poisoning effects.

Arsenic is a carcinogenic crystalline metalloid solid existing in the form of three allotropes. In the environment, it occurs mostly in the four oxidation states viz. $-\mathrm{III}, 0,+\mathrm{III}$ and $+\mathrm{V}$, of which $+\mathrm{III}$ and $+\mathrm{V}$ are the most common. As per WHO guideline, even 0.05 ppm concentration mark of

This is an Open Access article licensed under a Creative Commons license: Attribution 4.0 International (CC- BY). Published by Oriental Scientific Publishing Company @ 2018

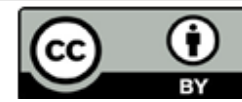


arsenic has now been considered to be unsafe for our mankind. WHO has recommended $0.01 \mathrm{ppm}$ level of arsenic toxicity to be the permissible limit in drinking water reducing it from $0.05 \mathrm{ppm}^{3}$. Keeping in mind about the human health issues, many countries have already been implemented this as safe guideline value.

In Bengal belt (Bangladesh, West Bengal and its adjoining area in India), there has been a huge burden of arsenic prompted diseases due to its continuous exposure in an elevated concentration for a long term. In these areas, the arsenic is mainly originated from geological sources and its uplifted concentration is concomitant with the reductive dissolution of iron pyrites or iron-oxyhydroxide, which promotes the mobilization of sorbed arsenic in the alluvium region of Ganga-Bhahmaputra river ${ }^{4,5}$. The obtainability of arsenic in groundwater is highly probable due to its immoderate use for irrigation.

The degree of toxicity of inorganic arsenite and arsenate are found to be much greater in comparison to the organic methylated arsenicals. Trivalent arsenicals are even more toxic than the pentavalent ones. The carcinogenic effect of arsenic in the light of molecular biology inhibits replication of DNA and interrupts the repair mechanism through the linkage with thiol groups. Exposure to arsenic repeatedly via drinking water from tube-well affects a large number of human organs showing acute symptoms of malignancy in the lungs, liver, bladder, kidney, urinary tract and skin. Prolonged arsenic ingestion in higher concentration has adverse effects on human cardiovascular system. It shows clinical symptoms of arsenical dermatitis, hyperkeratosis and may cause symptomatic Blackfoot Disease ${ }^{6}$.

Some widely used conventional low cost arsenic treatment technologies, viz. oxidation, co-precipitation, coagulation followed by flocculation, membrane filtration modified as electro-ultra filtration, adsorption using different solid materials, floatation and ion exchange etc. have been found to be reported in the developing countries ${ }^{7-11}$. A special priority has been given to the method of adsorption using different solid materials due to its easy handling and requirement of lesser volume for the treatment of greater arsenic concentration in groundwater. Several solid sorbent materials ${ }^{12,13}$ viz. activated carbon, agricultural residues and its by-products, industrial waste, biomasses and metal oxide nanoparticles are used extensively for the removal of arsenic contamination. Various mineralogical forms of mixed trivalent iron-aluminum oxide and hydroxide ${ }^{14-20}$, rare earth oxides ${ }^{21,22}$ and $\mathrm{Ce}$ (IV) doped iron oxide ${ }^{23}$ are found to be used in large scale as adsorbents for the removal of poisonous arsenic from the groundwater.

This work is mainly based on the removal of deadly arsenic from the contaminated groundwater using a potent low cost adsorbent, hydrated trivalent mixed iron-aluminum oxide by performing column experiment under different operating conditions. Here the efficiency of the adsorbent has been judged on the basis of varying column bed height and flow rate of the spiked effluent. The resulting data have been plotted in the breakthrough curves from which kinetic parameters using Thomas and Adams-Bohart models have been analyzed.

\section{MATERIALS AND METHODOLOGY}

\section{Preparation of hydrated mixed trivalent Iron- Aluminum oxide}

Equimolar (0.5 M) mixture of both $\mathrm{FeCl}_{3}$ and $\mathrm{AlCl}_{3}$ were taken together in an acidic solution of $0.1(\mathrm{M}) \mathrm{HCl}$. It was stirred thoroughly and heated to $60{ }^{\circ} \mathrm{C}$. The solution was made ammoniacal by adding $\mathrm{NH}_{4} \mathrm{OH}$ solution to it slowly with continuous stirring until the $\mathrm{pH}$ of the mixture attains almost neutrality. The dark brown colored gel-type slurry was formed. The overall solution along with the slurry was kept for aging for 30 hours. It was filtered and the gel-type precipitate was washed for four to five times with deionized water to make it free from other impurities. For making it dry completely, the slurry was transferred into a hot air oven. The pure solid product obtained was smashed in the form of fine grains having mesh size in the range of $0.14-0.29$ $\mathrm{mm}$. It was further heated for $3 \mathrm{~h}$ maintaining the temperature at about $120^{\circ} \mathrm{C}$ for re-drying. Finally, the grains were homogenized to $\mathrm{pH} 7.5$ and were ready to use as adsorbent for the column experiments.

\section{Reagents}

Ferric chloride hexahydrate $\left(\mathrm{FeCl}_{3} \cdot 6 \mathrm{H}_{2} \mathrm{O}\right)$ and potassium iodide (KI) were purchased from Merck, India. Aluminum Chloride hexahydrate $\left(\mathrm{AlCl}_{3} \cdot 6 \mathrm{H}_{2} \mathrm{O}\right)$ for adsorbent preparation and sodium borohydride $\left(\mathrm{NaBH}_{4}\right)$ for arsine formation were obtained from 
Loba Chemie, India. Silver diethyldithiocarbamate (SDDC) for arsenic adsorption purpose was procured from E. Merck, Germany. Ascorbic acid was purchased from SD Fine Chemicals, India. All other solvents and chemicals are either reagent or analytical grade and used as obtained.

\section{Instruments}

A digital electronic balance (Mettler AE-240) was used for different weighing purpose required for the experiment. For determination of $\mathrm{pH}$ of the solutions a pH meter (Elico LI 127) was utilized. A Fourier transform infrared spectrophotometer (Jasco 680 plus) was used for identification of the functional groups present in the oxides. For the spectral analysis of arsenic in the overall study an UV-Vis Spectrophotometer (Hitachi U3210) was also used.

\section{Source of the field sample}

Groundwater from about a 50 - $55 \mathrm{~m}$ deep tube well at M. G. road, Kolkata, West Bengal (India) was collected and analyzed for arsenic detection. After reproducing the data thrice, the concentration of arsenic was confirmed to be $2.2 \times 10^{-3} \mathrm{mg} / \mathrm{L}$ in the field groundwater. Solution containing As (III) from outside was spiked into the field groundwater sample until the concentration became $1.3 \times 10^{-1} \mathrm{mg} / \mathrm{L}$.

\section{Analytical methods}

In the field groundwater sample, the total dissolved inorganic arsenic was determined by the addition of $32 \%$ hydrochloric acid, $10 \%$ solution of potassium iodide and $1 \%$ solution of ascorbic acid, when reduction of arsenic took place from its pentavalent state to its trivalent one. It was then converted to arsine by using 3\% solution of sodium borohydride. The arsine gas generated was driven off by flushing nitrogen gas from a cylinder to the absorber assembly, and was absorbed in the chloroform solution of silver diethyldithiocarbamate (SDDC). The absorbance was measured at wavelength 520 $\mathrm{nm}$ against blank reagent using quartz spectrometer cuvette of $1 \mathrm{~cm}$ path length. The absorbance data was tallied with a standard calibration curve to compute the concentration of arsenic. The detection limit and accuracy of the method were found to be $1 \mu \mathrm{g}$ and $>90 \%$ respectively.

\section{Column experimental procedure}

In order to carry out column experiments ${ }^{24}$ for the removal of arsenic from groundwater using adsorption technique the adsorbent, hydrated trivalent mixed iron-aluminum oxide was uniformly packed in the glass tubes having internal diameter of $7 \mathrm{~mm}$ and a height of $250 \mathrm{~mm}$ over a glass wool sheet as per the height of the bed required for the accumulation of arsenic from polluted spiked sample water over column bed. The packing of this type of binary oxide in columns should be handled with utmost care; otherwise there will be chances of formation of cracks and void space in column bed which might hamper the easy flow of the effluent.

\section{Differential bed height of adsorbent}

Three different bed heights of the column were chosen for this adsorption experiment. For varying the heights of the column bed as $5 \mathrm{~cm}$, $6 \mathrm{~cm}$ and $7 \mathrm{~cm}$ the glass columns were required to be packed with $4.1 \mathrm{~g}, 5.1 \mathrm{~g}$ and $6.1 \mathrm{~g}$ of hydrated mixed trivalent iron-aluminum oxide respectively. The flow rate of the effluent was kept fixed at $1 \mathrm{~mL} / \mathrm{min}$. The arsenic concentration $\left(C_{0}\right)$ in the influent was $1.3 \times 10^{-1} \mathrm{mg} / \mathrm{L}$ and the effluents were collected in fractions in regular intervals in $50 \mathrm{~mL}$ volumetric flasks and the absorbance was measured.

\section{Outflow rate variation}

One particular column bed height was taken into consideration for the flow rate variation of the effluent. Three glass columns were packed with $6.1 \mathrm{~g}$ of hydrated trivalent mixed oxide of iron-aluminum to make the bed height $7 \mathrm{~cm}$. The field groundwater sample, spiked with $1.3 \times 10^{-1}$ $\mathrm{mg} / \mathrm{L}$ concentration of arsenic was passed through each column varying the outflow rates by $1 \mathrm{~mL}$, $3 \mathrm{~mL}$ and $5 \mathrm{~mL}$ per minute respectively. $100 \mathrm{~mL}$ volumetric flasks were used for the collection of effluents in a regular interval and the absorbance was measured in each case.

\section{Adsorption kinetic modeling}

For the elucidation of functioning and dynamic behavior of column studies two different adsorption kinetic models are well considered. Thomas and Adams-Bohart kinetic models have been chosen for better explanation. The models are given below.

\section{Thomas model}

One of the most extensively used fundamental kinetic models is the Thomas mode ${ }^{25}$ for the analysis of theoretical background of 
column performance. The model is based on some basic assumptions. The model assumes Langmuir isotherm of adsorption where reaction kinetics follows reversible pseudo second-order; axial and radial dispersions arising from kinetics of adsorption in the column bed are negligibly small; column void fraction is assumed to remain unchanged; physical properties of the solid adsorbent and the adsorbate are considered to be kept constant; during mass transfer the intra particle diffusion and external resistance are ignored directly. The mathematical expression for Thomas model is as follows:

$$
\mathrm{C}_{\mathrm{t}} / \mathrm{C}_{0}=1 /\left[1+\exp \left\{\left(\mathrm{k}_{\mathrm{Th}} \mathrm{q}_{0} \mathrm{x}\right) / v-\mathrm{k}_{\mathrm{Th}} \mathrm{C}_{0} \mathrm{t}\right\}\right]
$$

Where, $\mathrm{k}_{\mathrm{Th}}$ is the Thomas rate constant ( $\mathrm{mL} / \mathrm{min} . \mathrm{mg}), \mathrm{q}_{0}$ is equilibrium arsenic uptake per $\mathrm{g}$ of adsorbent or adsorption capacity $(\mathrm{mg} / \mathrm{g}), \mathrm{x}$ is the total mass of the adsorbent $(\mathrm{g}), v$ is the flow rate of the effluent $(\mathrm{mL} / \mathrm{min}), C_{t}$ is the effluent concentration $(\mathrm{mg} / \mathrm{L})$ of metal at any time $\mathrm{t}(\mathrm{min}), \mathrm{C}_{\mathrm{o}}$ is the influent metal concentration $(\mathrm{mg} / \mathrm{L})$ and $V_{\text {eff }}$ is the outflow volume $(\mathrm{mL})$ and $\mathrm{t}=\mathrm{V}_{\text {eff }} \mathrm{V} \cdot \mathrm{k}_{\mathrm{Th}}$ and $\mathrm{q}_{\mathrm{o}}$ values can be determined from the intercept and slope of the linear plot of $C_{t} / C_{o} V s$ ' $t$ '. This helps in explaining experimental data of the breakthrough curves.

\section{Adams-Bohart model}

Bohart and Adams ${ }^{26}$ model is used to justify the effectual behavior of column. An elementary equation was established to describe the relationship between $C_{t} / C_{o}$ and $t$. This model was set up initially for gases, later on it was transposed to liquids by changing the mathematical terms used in the expression. This model is used for the interpretation of the preliminary part of the breakthrough curve. This model is based on the assumption that the rate of adsorption is related to both the residual adsorbent capacity and the adsorbate concentration proportionally. The expression for the Adams-Bohart equation is given as.

$$
\mathrm{C}_{\mathrm{t}} / \mathrm{C}_{0}=\exp \left[\mathrm{k}_{\mathrm{AB}} \mathrm{C}_{0} \mathrm{t}-\mathrm{k}_{\mathrm{AB}} \mathrm{N}_{0}(\mathrm{Z} / \mathrm{F})\right]
$$

Where, $\mathrm{k}_{\mathrm{AB}}$ is the kinetic constant $(\mathrm{L} / \mathrm{mg}$. $\mathrm{min}), \mathrm{F}$ is the linear flow rate $(\mathrm{cm} / \mathrm{min})$ or superficial velocity (the volumetric flow rate/the column section area), $Z$ is the bed-height ( $\mathrm{cm}$ ) of the column and $\mathrm{N}_{0}$ is the saturation concentration (mg/L). Rest parameters are same as narrated in the Thomas model. The constant values are calculated from the plot of $C_{t} / C_{0}$ against time (t) ( $\mathrm{min}$ ) for the breakthrough curves.

\section{RESULTS AND DISCUSSION}

\section{Characterization of hydrated mixed trivalent Iron-Aluminum oxide}

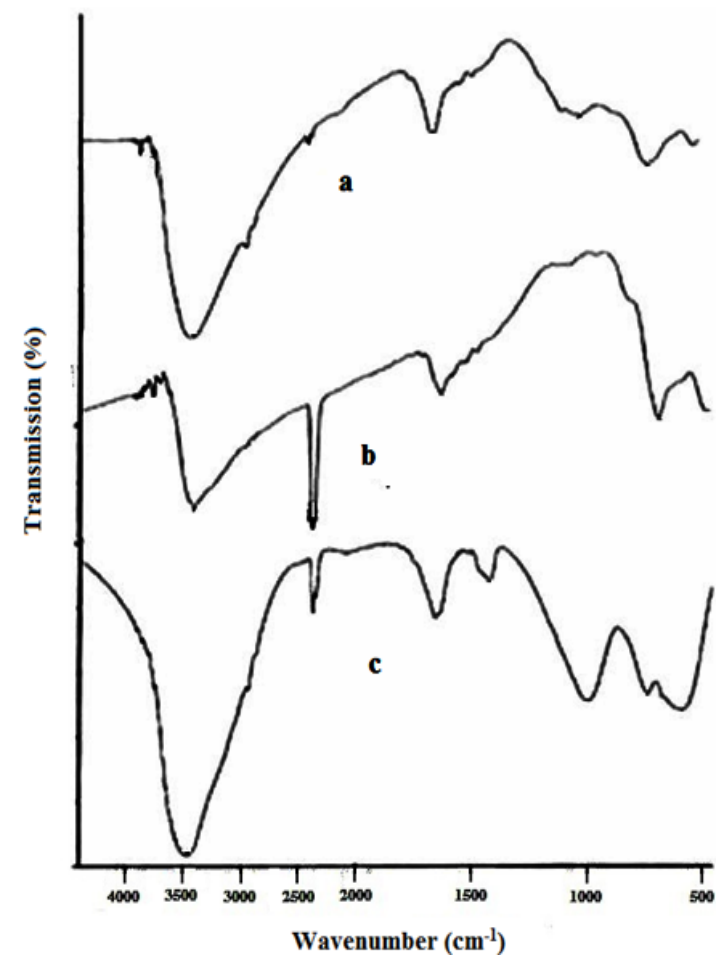

Fig. 1. FTIR-spectra of (a) Equimolar mixed trivalent $\mathrm{Fe}_{2} \mathrm{O}_{3}-\mathrm{Al}_{2} \mathrm{O}_{3}$ (b) Pure $\mathrm{Fe}_{2} \mathrm{O}_{3}$ (c) Pure $\mathrm{Al}_{2} \mathrm{O}_{3}$

The Fourier transform infrared (FTIR) spectra $\mathrm{a}, \mathrm{b}$ and $\mathrm{C}$ in Fig. 1 represents that of equimolar mixed trivalent $\mathrm{Fe}_{2} \mathrm{O}_{3}-\mathrm{Al}_{2} \mathrm{O}_{3}$, pure $\mathrm{Fe}_{2} \mathrm{O}_{3}$ and pure $\mathrm{Al}_{2} \mathrm{O}_{3}$ respectively. The spectra of three types of oxides showed a large no. of peaks and bands of variable intensities within the range of $4000-500 \mathrm{~cm}^{-1}$, but attempt has not been made to assign each and every separate band of specific wave numbers. A broad band above $3300 \mathrm{~cm}^{-1}$ has been assigned to the symmetrical and asymmetrical stretching of bound $\mathrm{H}_{2} \mathrm{O}$ molecule $\mathrm{O}-\mathrm{H}$ bond. A strong band identified in the range $1630-1650 \mathrm{~cm}^{-1}$ is allocated to the bending mode of hydroxyl $(-\mathrm{OH})$ group. The bands at 694 and $478 \mathrm{~cm}^{-1}$ of spectrum a (Fig. 1), which is of binary oxide are attributed to the symmetrical and asymmetrical stretches of $\mathrm{M}$ (metal)- $\mathrm{O}$ bonds. Those bands in spectrum $\mathrm{b}$ are 
found at 672 and $465 \mathrm{~cm}^{-1}$ and the same bands for spectrum $c$ are at positions 732 and $580 \mathrm{~cm}^{-1}$. Furthermore, the wave numbers almost at 981 and $1467 \mathrm{~cm}^{-1}$ are assumed to be due to hydroxide bridging between the two hetero-metal ions present in the mixed trivalent oxide, referred to as symmetric and asymmetric bending frequencies.

\section{Impact on breakthrough curve for variation of adsorbent bed height}

The dependence of bed depth on breakthrough curve has been investigated by passing $1.30 \times 10^{-1} \mathrm{mg} / \mathrm{L}$ concentration of influent through the three columns packed with $4.1,5.1$ and $6.1 \mathrm{~g}$ of hydrated trivalent iron-aluminum mixed oxide as the adsorbent. The column heights became $5.0,6.0$ and $7.0 \mathrm{~cm}$ respectively and the flow rate of the effluent has been maintained at $1 \mathrm{~mL} /$ minute. The breakthrough curve of $\mathrm{C}_{t} / \mathrm{C}_{\mathrm{O}}$ vs time (min) has been manifested in Fig. 2, where $\mathrm{C}_{\mathrm{t}}$ is the outflow concentration at time $(\mathrm{t})$ and $\mathrm{C}_{\mathrm{o}}$ is the initial input concentration of trivalent arsenic.

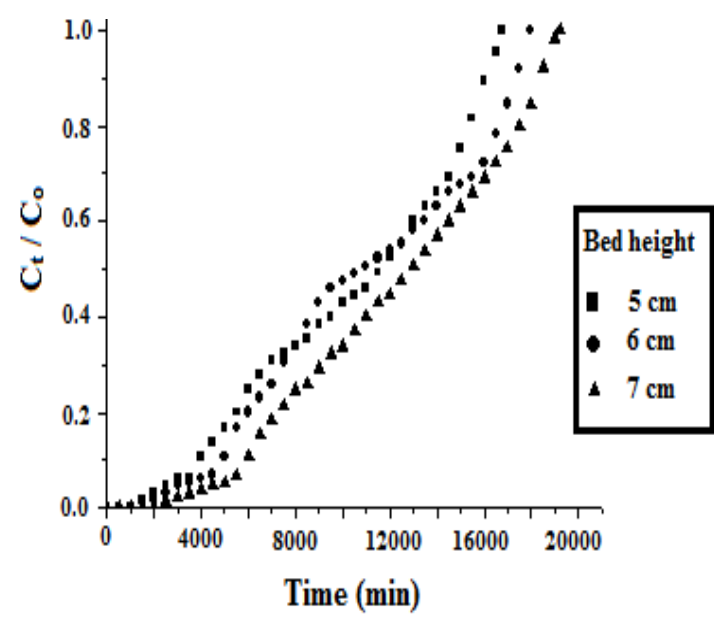

Fig. 2. Influence on breakthrough curve with variable bed heights of hetero-oxide adsorbent

It has been observed from the plot that the shape and the inclination of the curves are somewhat different from each other with bed height variation. The break point reaches faster in the columns with lower bed depth. The higher uptake and gradual increase in slope of the breakthrough curves were observed at the initial stage of the curves. This gradual increase was continued up to the break point of the curve, but the arsenic concentration in the outflow was found to be increased readily after the break point is attained so as the slope of the curve. The columns with lower bed depth get saturated faster than the higher ones. The breakthrough volumes for the columns with bed height 5.0, 6.0 and $7.0 \mathrm{~cm}$ are 3900,5100 and $6600 \mathrm{~mL}$ respectively. This was due to the rise in the empty bed contact time (EBCT) with increasing the bed depth. The EBCT for the columns with bed heights 5.0, 6.0 and $7.0 \mathrm{~cm}$ were $1.82,2.23$ and 2.91 min respectively. With increased EBCT, the diffusion process had become so effective and faster that the breakthrough volume $\left(\mathrm{V}_{\mathrm{b}}\right)$ becomes more and the breakthrough time $\left(t_{b}\right)$ reaches later ${ }^{27,28}$. With increasing EBCT, the influent and the adsorbent in between contact time has been escalated and a higher amount of adsorbate had got adsorbed by the column bed and hence the $V_{b}$ has been increased with the rise of bed height.

The parameters calculated from the breakthrough curves varying the bed heights of the adsorbent from $5-7 \mathrm{~cm}$ at a fixed outflow rate using Thomas and Adams-Bohart kinetic models analyses have been represented in Table 1 and Table 2 respectively. For Thomas model, the Thomas rate constant $\left(\mathrm{k}_{\mathrm{Th}}\right)$ has been found to be increased and the equilibrium arsenic uptake per gram of adsorbent i.e., the maximum adsorption capacity $\left(\mathrm{q}_{0}\right)$ is decreased with the rise of column bed depth. The rise of the $\mathrm{k}_{\mathrm{Th}}$ values can be justified considering the fact of decrease in the mass transport resistance with rise in the adsorbent bed height ${ }^{29}$. The changes in the parameters are related to the increase in empty bed contact time (EBCT) of the adsorbate with the active sites of the adsorbent, as with increasing the EBCT values the rate of sorption process is increased. For Adams-Bohart model the values of the kinetic constant $\left(\mathrm{k}_{\mathrm{AB}}\right)$ and the saturation concentration $\left(\mathrm{N}_{\mathrm{o}}\right)$ have been evaluated. The changes in the values of $\mathrm{k}_{\mathrm{AB}}$ and $\mathrm{N}_{\mathrm{o}}$ are due to the influence of mass transfer phenomenon particularly in order to explain the preliminary part of the adsorption process and the breakthrough curve analysis ${ }^{30,31}$.

\section{Variation of flow rate and its impact on the breakthrough curve}

The results demonstrated in Fig. 5 show the influence of the flow rate of the effluent on the breakthrough curve for the removal of arsenic at a fixed bed depth $(7 \mathrm{~cm})$ of hydrated mixed trivalent iron-aluminum oxide column. 


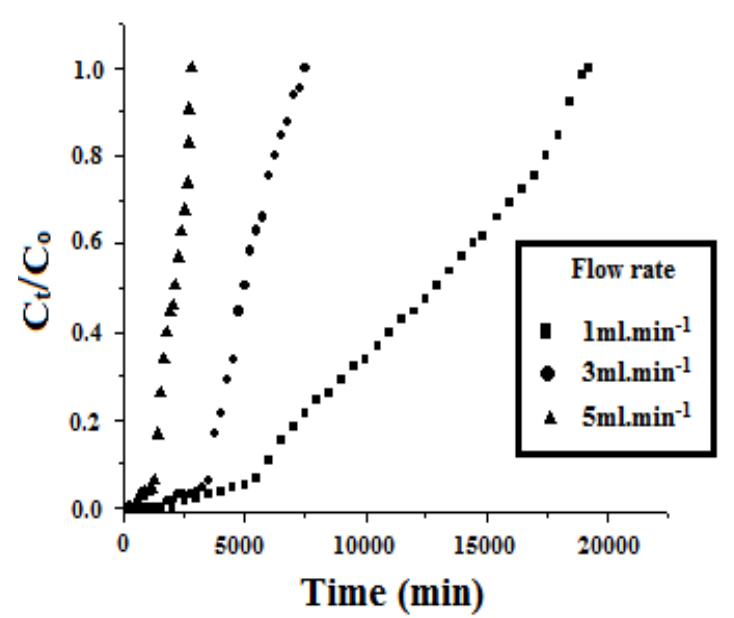

Fig. 3. Impact of flow-rate variation of effluent on breakthrough curve

It was found that the breakthrough volumes $\mathrm{V}_{\mathrm{b}}(\mathrm{mL})$ for the variable outflow rates $(\mathrm{mL} / \mathrm{min}) 1.0$, 3.0 and 5.0 were 6600,3500 and 1600 for arsenic (Fig. 3), respectively.

The increase in the rate of outflow results in decrease of the breakthrough volume as well as the breakthrough time. It has been aroused from the gradual decrease of EBCT ( $\mathrm{min}$ ) from 2.91 to 1.57 to 0.65 with increase in the rate of flow of influent arsenic 1.0, 3.0 and $5.0 \mathrm{~mL} / \mathrm{min}$ respectively. With lowering of EBCT, the diffusion process becomes less potent which had resulted in lesser extent of adsorption ${ }^{27,28}$. Thus, longer time will be needed for the adsorbent to get bonded to the metal ion effectively. The column studies report states that the plateau of the breakthrough curve has reached faster with increase in the flow rate of the effluent. This is because of much reduced contact time spent between the solute present in the influent and the surface of the column bed of the adsorbent and the adsorption front reaches the bottom of the column quickly.

The values determined from the breakthrough curves using the two kinetic models at variable flow rates are summarized in Table 1 and Table 2. Similarly as in the case for variable bed heights, here also with increasing outflow rates the adsorption model parameters can also be correlated to the decrease in the EBCT values and lowering in the mass transport resistance in the liquid film. Here in case of Thomas model, there occurs a rise in the $k_{T h}$ values and a decrease in the $q_{0}$ values with increase in the volumetric flow rate at a particular bed height of the column ${ }^{29-31}$. In case of Adams-Bohart model, the variation in the $\mathrm{k}_{\mathrm{AB}}$ and $\mathrm{N}_{\mathrm{o}}$ values with increase in the effluent flow rate and decrease in EBCT is quite significant. Thus kinetic modeling can be employed successfully to describe the behavior of adsorption in the column experiment.

Table 1: Kinetic parameters calculated from the breakthrough curves using Thomas model under variable conditions at $C_{0}=1.30 \times 10^{-1} \mathrm{mg} / \mathrm{L}$

\begin{tabular}{|c|c|c|c|c|}
\hline Bed height(cm) & Flow rate $(\mathrm{mL} / \mathrm{min})$ & $\mathrm{EBCT}(\min )$ & $\mathrm{k}_{\mathrm{Th}}(\mathrm{mL} / \mathrm{min} . \mathrm{mg})$ & $q_{0}(m g / g)$ \\
\hline 5 & 1 & 1.82 & 2.545 & 0.569 \\
\hline 6 & 1 & 2.23 & 2.584 & 0.419 \\
\hline 7 & 1 & 2.91 & 2.907 & 0.416 \\
\hline 7 & 3 & 1.57 & 13.384 & 0.178 \\
\hline 7 & 5 & 0.65 & 22.164 & 0.059 \\
\hline
\end{tabular}

Table 2: Kinetic parameters calculated from the breakthrough curves using Adams-Bohart model under variable conditions at $C_{0}=1.30 \times 10^{-1} \mathrm{mg} / \mathrm{L}$

\begin{tabular}{ccccc}
\hline Bed Height $(\mathrm{cm})$ & Flow Rate $(\mathrm{mL} / \mathrm{min})$ & $\mathrm{EBCT}(\mathrm{min})$ & $\mathrm{k}_{\mathrm{AB}}(\mathrm{L} / \mathrm{mg} \cdot \mathrm{min}) \times 10^{-3}$ & $\mathrm{~N}_{\mathrm{o}}(\mathrm{mg} / \mathrm{L}) \times 10^{3}$ \\
\hline 5 & 1 & 1.82 & 1.087 & 1.619 \\
6 & 1 & 2.23 & 1.158 & 1.382 \\
7 & 1 & 2.91 & 1.357 & 1.326 \\
7 & 3 & 1.57 & 4.601 & 1.086 \\
7 & 5 & 0.65 & 10.563 & 0.697 \\
\hline
\end{tabular}

Scrutinization of some parameters for quality in Table 3. Also, their corresponding values after analysis of water

Some parameters for checking water quality of the field sample were analyzed and summarized passing through the column bed of adsorbent of different bed heights at break point were collectively shown in Table 4. 
Table 3: Parameters for water quality analysis $(\mathrm{mg} / \mathrm{L})$ of the field sample before treatment through the column bed

\begin{tabular}{ccccccccc}
\hline Water quality parameters & $\mathrm{pH}$ & $\mathrm{Fe}^{2+}$ & $\mathrm{F}^{-}$ & $\mathrm{HCO}_{3}^{-}$ & Hardness & $\mathrm{Ca}^{2+}$ & $\mathrm{Cl}^{-}$ & $\mathrm{TDS}^{2}$ \\
Before filtration & 7.3 & 0.21 & 0.45 & 1350 & 194 & 139 & 558 & 750 \\
\hline
\end{tabular}

Table 4: Parameters for water quality analysis $(\mathrm{mg} / \mathrm{L})$ of the field sample after passing through the column bed at break point

\begin{tabular}{cccc}
\hline $\begin{array}{c}\text { Water Quality } \\
\text { Parameters }\end{array}$ & \multicolumn{2}{c}{ After filtration through the column with bed } \\
height & \\
\hline & $5 \mathrm{~cm}$ & $6 \mathrm{~cm}$ & $7 \mathrm{~cm}$ \\
\hline $\mathrm{Fe}^{2+}$ & 0.021 & 0.017 & 0.013 \\
$\mathrm{Ca}^{2+}$ & 27 & 24 & 22.4 \\
$\mathrm{~F}^{-}$ & 0.15 & 0.11 & 0.06 \\
$\mathrm{Cl}^{-}$ & 340 & 327 & 318 \\
$\mathrm{HCO}_{3}^{-}$ & 631 & 558 & 432 \\
$\mathrm{Hardness}$ & 130 & 100 & 97 \\
TDS & 43 & 41 & 37 \\
\hline
\end{tabular}

\section{CONCLUSION}

The break through analysis is the preliminary investigation to precede the experimental work from the batch analysis study to its further application. In this work, the column study had been carried out to set up a suitable and effective application system that can be employed for the removal of arsenic present in much higher concentration than its permissible limit in contaminated groundwater. Here hydrated trivalent mixed iron-aluminum oxide was successfully utilized as column bed adsorbent to eliminate arsenic from the influent. The breakthrough curves have been studied thoroughly and the maximum adsorption capacities have been evaluated with the variation of both bed height of the adsorbent and flow rate of the effluent. With decrease in the rate of outflow and rise in the bed height of the column, the breakthrough volume has been found to be increased due the enhancement of empty bed contact time (EBCT). Column performance investigations using hydrated trivalent iron-aluminum hetero-oxide packed beds stipulate that its effectiveness for the arsenic removal is appreciable. Thus hydrated iron- aluminum binary oxide can be used as a potential, cost effective removing agent for eliminating this toxic metal from groundwater. The kinetic parameters using Thomas and Adams-Bohart models were predicted successfully and they were in good agreement with the experimentally determined EBCT values. This method of adsorption is a green chemistry based technology because it requires no extra energy to run the removal process. Nevertheless, this remediation technique can be considered as a safe option for the disposal of the arsenic from polluted groundwater.

\section{ACKNOWLEDGEMENT}

Author thanks the authorities of her college for various supports. Author also likes to acknowledge Prof. U. C. Ghosh, Department of Chemistry, Presidency College, Kolkata (currently recognized as Presidency University) for his helps.

\section{Conflicts of interests}

No conflict of interests

\section{REFERENCES}

1. Mukherjee, A.; Fryar, A. E.; Eastridge, E. M.; Nally, R. S.; Chakraborty, M.; Scanlon B. R. Sci. Total Environ., 2018, 645, 1371-1387.

2. Muehe, E. M.; Kappler, A. Environ. Chem., 2014, 11(5), 483-495.

3. Ravenscroft, P.; Brammer, H.; Richards, K. Arsenic Pollution: A Global Synthesis., chapter five., 2009, 157-212.

4. Bindal, S.; Singh, C. K. Water Res., 2019, 159, 65-76.

5. Berube, M.; Jewell, K.; Myers, K. D.; Knappett, P. S. K.; Shuai, P.; Hossain, A.; Lipsi M.; Hossain, S.; Hossain, A.; Aitkenhead-
Peterson, J.; Ahmed, K. M.; Datta, S. Environ. Chem., 2018, 15(2), 29-45.

6. Lamm, S. H.; Robbins, S. A.; Zhou, C.; Lu, J.; Chen, R.; Feinleib, M. Regul. Toxicol. Pharmacol., 2013, 65, 147-156.

7. Samah, N. A. N.; Rosli, N. A. M.; Manap, A. H. A.; Aziz, Y. F. A.; Yusoff, M. M. Chem. Eng. J., 2020, 394, 124900. DOI:10.1016/j.cej.2020.124900.

8. Kowalski, K. P. Chemistry of Advanced Environmental Purification Processes of Water., 2014, 8, 285-337.

9. Nidheesh, P. V.; Anantha Singh, T. S. Chemosphere., 2017, 181, 418-432. 
10. Zhu, N.; Qiao, J.; Ye, Y.; Yan, T. J. Environ. Manage., 2018, 211, 73-82.

11. Mohan, D.; Pittman, C. U. J. Hazard. Mater., 2007, 142(1-2), 1-53.

12. Corsini, A.; Cavalca, L.; Muyzer, G.; Zaccheo, P. Environ. Chem., 2014, 11(5), 558-565.

13. Wong, S.; Ngadi, N.; Inuwa, I. M.; Hassan, O. J. Clean. Prod., 2018, 175, 361-375.

14. Xiong, Y.; Tong, Q.; Shan, W.; Xing, Z.; Wang, Y.; Wen, S.; Lou, Z. Appl. Surf. Sci., 2017, 416, 618-627.

15. Maghsodi, A.; Adlnasab, L.; Shabanian, M.; Javanbakht, M. Ultrason. Sonochem., 2018, 48, 441-452.

16. Nieto-Delgado, C.; Gutierrez-Martinez, J.; Rangel-Mendez, R. J. Environ. Sci., 2018, 76, 403-414.

17. Sidddiqui, S. I.; Chaudhry, S. A. Process Saf. Environ., 2017, 111, 592-626.

18. Giles, D. E.; Mohapatra, M.; Issa, T. B.; Anand, S.; Singh, P. J. Environ. Manage., 2011, 92, 3011-3022.

19. Yin, H., Kong; M., Gu. X.; Chen, H. J. Clean. Prod., 2017, 166, 88-97.

20. Pawar, R. R.; Lalhmunsiama, Kim, M.; Kim, J. G.; Hong, S. M.; Sawant, S. Y.; Lee, S. M. Appl. Clay Sci., 2018, 162, 339-350.
21. Yu, Y.; Yu, L.; Koh, K. Y.; Wang, C.; Chen, J. P. Crit. Rev. Env. Sci. Tec., 2018, 1127-1164.

22. Lee, S. H.; Kim, K. W.; Lee, B. T.; Bang, S.; Kim, H.; Kang, H.; Jang, A. Int. J. Environ. Res. Public Health., 2015, 12(10), 13523-13541.

23. Wen, Z.; Ke, J.; J. Xu; Guo, S.; Zhang, Y.; Chen, R. Chem. Eng. J., 2018, 343, 416-426.

24. Lehman, M.; Zouboulis, A. I. and Matis, K. A. Environ. Pollut., 2001, 113, 121-128.

25. Thomas, H. C. J. Am. Chem. Soc., 1944, 66(10), 1664-1666.

26. Bohart, G. S.; Adams, E. Q. J. Am. Chem. Soc., 1920, 42(3), 523-544.

27. Pokhrel, D.; Viraraghavan, T. Bioresour. Technol., 2008, 99(6), 2067-2071.

28. Ko, D. C. K.; Porter, J. F.; McKay, G. Ind. Eng. Chem. Res., 1999, 38(12), 4868-4877.

29. Borba, C. E.; Guirardello, R.; Silva, E. A.; Veit, M. T.; Tavares, C. R. G. Biochem. Eng. J., 2006, 30, 184-191.

30. Radhika, R.; Jayalatha, T.; Rekha Krishnan, G.; Jacob, S.; Rajeev, R.; George, B. K. Process Saf. Environ., 2018, 117, 350-362.

31. Sekhula, M. M.; Okonkwo, J. O.; Zvinowanda, C. M.; Agyei, N. N.; Chaudhary, A. J. J. Chem. Eng. Process Technol., 2012, 3(2). 